\title{
Numerical Simulation of Recycled Concrete Using Convex Aggregate Model and Base Force Element Method
}

\author{
Yijiang Peng, Hao Chu, and Jiwei Pu \\ The Key Laboratory of Urban Security and Disaster Engineering, Ministry of Education, \\ Beijing University of Technology, Beijing 100124, China \\ Correspondence should be addressed to Yijiang Peng; pengyijiang@bjut.edu.cn
}

Received 9 May 2016; Revised 4 August 2016; Accepted 26 September 2016

Academic Editor: Ana S. Guimarães

Copyright (C) 2016 Yijiang Peng et al. This is an open access article distributed under the Creative Commons Attribution License, which permits unrestricted use, distribution, and reproduction in any medium, provided the original work is properly cited.

By using the Base Force Element Method (BFEM) on potential energy principle, a new numerical concrete model, random convex aggregate model, is presented in this paper to simulate the experiment under uniaxial compression for recycled aggregate concrete (RAC) which can also be referred to as recycled concrete. This model is considered as a heterogeneous composite which is composed of five mediums, including natural coarse aggregate, old mortar, new mortar, new interfacial transition zone (ITZ), and old ITZ. In order to simulate the damage processes of RAC, a curve damage model was adopted as the damage constitutive model and the strength theory of maximum tensile strain was used as the failure criterion in the BFEM on mesomechanics. The numerical results obtained in this paper which contained the uniaxial compressive strengths, size effects on strength, and damage processes of RAC are in agreement with experimental observations. The research works show that the random convex aggregate model and the BFEM with the curve damage model can be used for simulating the relationship between microstructure and mechanical properties of RAC.

\section{Instruction}

Recycled aggregate concrete (RAC) is considered as a green building material which can alleviate the pressure of resource shortage. Since more and more researchers were attracted to carry out a series of experiments to explore the mechanical performances of RAC, some classical conclusions have been made over the micro-, meso-, and macroscales. However, testing always consumes a large amount of manpower, material, and financial resources, and the conclusions made by different researchers are not very coincident frequently.

Based on the concept of numerical concrete presented by Wittmann et al. [1], the random aggregate model was proposed to simulate the failure mechanism of concrete in recent years. Bažant et al. [2] assumed concrete as two-phase composites composed of cement mortar and aggregate and presented the random particle model to simulate the spread of cracking in concrete. Liu and Wang [3] presented the random circular aggregate model and simulated the whole failure process of concrete under uniaxial tensile by using nonlinear finite element method (FEM). Zhu and Tang [4] proposed a new mechanical model to simulate the damage-fracture process of concrete under shear loading by using displacementcontrolled FEM. Chen et al. [5] used three-dimensional random aggregate model to simulate the fracture processes of damage evolution and the conformation of cracks in dam concrete. Du et al. [6-9] proposed a mesoelement equivalent method which is based on random circular aggregate model to research macromechanical properties of concrete. Later on, a mesoscale analysis method was applied to the simulation of nonlinear damage and failure behavior of reinforced concrete specimens by $\mathrm{Du}$ et al. [10]. Xiao et al. [11] analyze the mechanical properties of interfacial transition zones (ITZs) of RAC by using modeled recycled aggregate concrete.

However, the simulation of random circular aggregate model is more suitable for boulder concrete than crushed stone concrete. Although some studies on the random convex polygon aggregate model of concrete were done $[12,13]$, few researchers applied the random convex polygon aggregate model to RAC.

In recent years, a new type of FEM, the Base Force Element Method (BFEM), has been developed by Peng et al. 


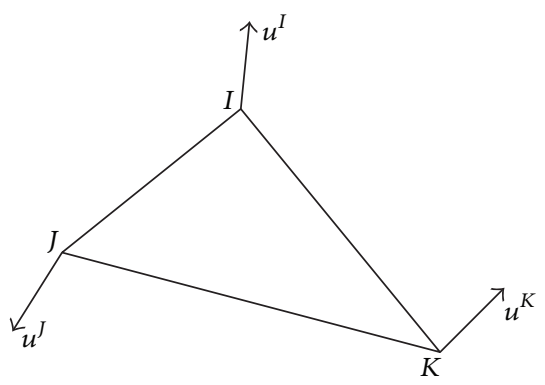

Figure 1: A triangular element.

[14-21]. In this paper, the BFEM on potential energy principle are used to analyze uniaxial compression characteristics of different sizes of RAC specimens on mesolevel. In order to reflect the test condition more factually, a new random aggregate model (random convex aggregate model) is presented for RAC. Meanwhile, this numerical simulation applied the piecewise curve of damage constitutive model based on the nonlinear damage mechanics to the destruction judgement for RAC material, and the results of the numerical simulation conform to the test result.

\section{The Model of Base Force Element Method}

The concept of base forces was proposed by Gao [22]. The base forces are used to replace various stress tensors for the description of the stress state at a point. These base forces can be directly obtained from the strain energy. By means of the base forces, the equilibrium equation, boundary condition, and elastic law are written in very simple forms. For large deformation problems, the derivation of basic formulae was simplified.

The Base Force Element Method (BFEM) on complementary energy principle uses the base forces as fundamental variables to establish control equations of the novel finite element method. In the literature [22], Gao gave an new idea of deriving compliance matrix of an arbitrary polyhedron element. Peng et al. [21] gave an explicit expression of the compliance matrix and derived governing equations of the BFEM on complimentary energy principle using the Lagrange multiplier method. The new finite element method based on the concept of base forces was called the Base Force Element Method by Peng and Liu [14].

The BFEM on potential energy principle uses the displacement gradients $u_{i}$ which are the conjugate variables of base forces $\mathbf{T}^{i}$ to establish control equations of the new finite element method. Peng et al. [21] derived governing equations of the BFEM on potential energy principle using Gao's thought [22] for a triangular element as shown in Figure 1. The stiffness matrix of a base force element [21] can be obtained as

$$
\begin{array}{r}
\mathbf{K}^{I J} \\
=\frac{E}{2 A(1+\nu)}\left[\frac{2 \nu}{1-2 \nu} \mathbf{m}^{I} \otimes \mathbf{m}^{J}+m^{I J} \mathbf{U}+\mathbf{m}^{J} \otimes \mathbf{m}^{I}\right] \\
(I=1,2,3 ; \quad J=1,2,3),
\end{array}
$$

where $E$ is Young's modulus of an element, $v$ is Poisson's ratio, $A$ is the area of the element, $\mathbf{U}$ is the unit tensor, expressed as $\mathbf{U}=\mathbf{P}_{\alpha} \otimes \mathbf{P}^{\alpha}=\mathbf{P}^{\alpha} \otimes \mathbf{P}_{\alpha}, m^{I J}=\mathbf{m}^{I} \cdot \mathbf{m}^{J}$, and $\mathbf{m}^{I}$ can be calculated from

$$
\mathbf{m}^{I}=m_{\alpha}^{I} \mathbf{P}_{\alpha}=\frac{1}{2}\left(L_{I J} \mathbf{n}^{I J}+L_{I K} \mathbf{n}^{I K}\right),
$$

where $\mathbf{P}_{\alpha}$ is the basic vector and $\mathbf{P}^{\alpha}$ is the conjugate vector of $\mathbf{P}_{\alpha}, L_{I J}$ and $L_{I K}$ are the length of edges $I J$ and $I K$ of the element, and $\mathbf{n}^{I J}$ and $\mathbf{n}^{I K}$ denote the external normal of edges $I J$ and $I K$, respectively.

For the plane stress problem, it is necessary to replace $E /\left(1-v^{2}\right)$ by $E$ and $v /(1-v)$ by $v$ in $(1)$.

\section{Damage Constitutive Model of Materials}

Generally, the nonlinear performance of concrete stressstrain curve can be mainly attributed to the continuous quasibrittle damage, caused by the initiation and propagation of microcracks under stress, rather than the plastic deformation of materials. Therefore, the RAC which is composed by different characteristics of natural coarse aggregate, new mortar, old mortar, and new and old interfacial transition zone (ITZ) on mesolevel can be described by the constitutive relation of elasticity mechanics.

According to the Lemaitre strain equivalent principle [23], the strain in damaged materials caused by the stress $\sigma$ is as equal as the strain in nondestructive materials caused by the nominal stress $\widetilde{\sigma}$, and its expression is as follows:

$$
\varepsilon=\frac{\sigma}{E}=\frac{\widetilde{\sigma}}{E}=\frac{\sigma(1-D)}{E_{0}}
$$

or

$$
\sigma=E_{0}(1-D) \varepsilon
$$

where $E$ and $E_{0}$ represent damaged elastic modulus and initial elastic modulus, respectively. $D$ is damage variable.

In order to reflect the damage processes of materials veritably, the damage degradation of recycled aggregate concrete is described by the revised piecewise curve damage model which was first presented by Qian and Zhou [24]. The revised model is shown in Figure 2, where the damage factor $D$ can be expressed as follows:

$$
D= \begin{cases}A_{1}\left(\frac{\varepsilon}{\varepsilon_{f}}\right)^{B_{1}}, & 0 \leq \varepsilon<\varepsilon_{f}, \\ 1-\frac{A_{2}}{C_{1}\left(\varepsilon / \varepsilon_{f}-1\right)^{B_{2}}+\varepsilon / \varepsilon_{f}}, & \varepsilon_{f} \leq \varepsilon<\varepsilon_{r}, \\ 1-\frac{\sigma_{r}}{E \varepsilon}, & \varepsilon_{r} \leq \varepsilon<\varepsilon_{u}, \\ 1, & \varepsilon \geq \varepsilon_{u} .\end{cases}
$$

In Figure 2, $\sigma_{f}$ is the peak tensile stress of each relevant element in RAC, and $\varepsilon_{f}$ is the tensile strain corresponding to 


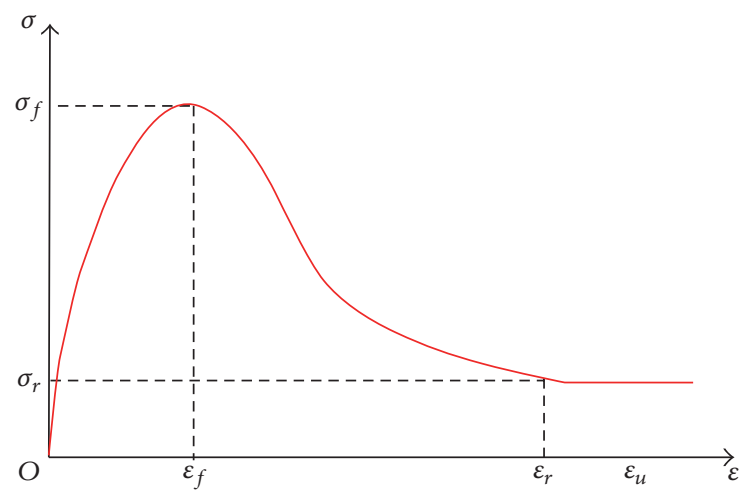

Figure 2: Revised piecewise curve of damage model.

the peak tensile stress. The residual tensile strength is defined as $\sigma_{r}=\lambda \sigma_{f}, \lambda$ being the residual strength coefficient, ranging from 0 to 1 . Accordingly, the residual strain is defined as $\varepsilon_{r}=\eta \varepsilon_{f}$, where $\eta$ is the residual strain coefficient. Ultimate strain is defined as $\varepsilon_{u}=\xi \varepsilon_{f}$, where $\xi$ is the ultimate strain coefficient.

According to (5), when $\varepsilon \geq \varepsilon_{r}$, macrocrack will appear and develop till the components damage. $B_{2}$ and $C_{1}$ are parameters of curve. $A_{1}, A_{2}$, and $B_{1}$ are material constants, which can be obtained by boundary condition of $\left.\sigma\right|_{\varepsilon=\varepsilon_{f}}=\sigma_{f}$ and $\left.(\mathrm{d} \sigma / \mathrm{d} \varepsilon)\right|_{\varepsilon=\varepsilon_{f}}=0$, and they are expressed as follows:

$$
\begin{aligned}
& A_{1}=\frac{E_{0} \varepsilon_{f}-\sigma_{f}}{E_{0} \varepsilon_{f}}=1-\frac{E_{f}}{E_{0}}, \\
& A_{2}=\frac{\sigma_{f}}{E_{0} \varepsilon_{f}}=\frac{E_{f}}{E_{0}}=1-A_{1}, \\
& B_{1}=\frac{\sigma_{f}}{E_{0} \varepsilon_{f}-\sigma_{f}}=\frac{E_{f}}{E_{0}-E_{f}},
\end{aligned}
$$

where $E_{f}$ is the elastic modulus at the time when strain reaches $\varepsilon_{f}$.

In this paper, the failure criterion of RAC is the strength theory of maximum tensile strain, which means $\varepsilon$ in damage evolution equation is defined as the principal tensile strain of each element.

\section{Random Aggregate Model for RAC}

4.1. Random Circular Aggregate Model. In order to obtain more optimized compaction and macroscopic strength of RAC, the Fuller grading curve was adopted to simulate the distribution of the aggregate model in this paper. Based on this curve, Walraven and Reinhardt [25] translated the threedimensional aggregate grading curve into the planer aggregate grading curve which located in the sectional plane of concrete specimens. The cumulative probability distribution of different particle diameter of aggregates and the numbers of circular coarse aggregate particles with various sizes in the numerical concrete models can be confirmed, respectively. This simulation chooses $42 \%$ as the mass fraction of old cement mortar in each recycled aggregate; then the thickness of old cement mortar in RAC can also be figured out.

In this present paper, three dimensions of specimens for RAC, contained $100 \mathrm{~mm} \times 100 \mathrm{~mm} \times 100 \mathrm{~mm}, 150 \mathrm{~mm} \times$ $150 \mathrm{~mm} \times 150 \mathrm{~mm}$ and $300 \mathrm{~mm} \times 300 \mathrm{~mm} \times 300 \mathrm{~mm}$ are used to simulate the uniaxial compression tests.

By the above mentioned method, the three-dimensional structure is schematized as a plane stress problem and the simplified sizes of specimens are $100 \mathrm{~mm} \times 100 \mathrm{~mm}, 150 \mathrm{~mm}$ $\times 150 \mathrm{~mm}$, and $300 \mathrm{~mm} \times 300 \mathrm{~mm}$.

For the specimens of $100 \mathrm{~mm} \times 100 \mathrm{~mm}$, the numbers of large aggregate (typical diameter is $17.5 \mathrm{~mm}$ ), middle aggregate (typical diameter is $12.5 \mathrm{~mm}$ ), and fine aggregate (typical diameter is $7.5 \mathrm{~mm}$ ) in RAC are 3, 9, and 37, respectively.

Analogously, for the specimens of $150 \mathrm{~mm} \times 150 \mathrm{~mm}$, the numbers of large aggregate (typical diameter is $35 \mathrm{~mm}$ ), middle aggregate (typical diameter is $20 \mathrm{~mm}$ ), and fine aggregate (typical diameter is $10 \mathrm{~mm}$ ) in RAC are 3,10 , and 59 , respectively.

For the specimens of $300 \mathrm{~mm} \times 300 \mathrm{~mm}$, the numbers of large aggregate (typical diameter is $60 \mathrm{~mm}$ ), middle aggregate (typical diameter is $30 \mathrm{~mm}$ ), and fine aggregate (typical diameter is $12 \mathrm{~mm}$ ) in RAC are 6, 21, and 159, respectively.

The random circular aggregate distribution model (presented in Figure 3) can be generated by Monte Carlo method which can create the centroid coordinates of all kinds of coarse aggregate particles randomly.

4.2. Random Convex Aggregate Model. The formation of the random convex aggregate model for RAC is based on the random circular aggregate model which contained the data of the aggregate particle diameter, the number of different sizes of aggregates, and the thickness of old cement mortar.

Firstly, the basic framework of random convex aggregate can be generated by the internal access polygon of each aggregate boundary with the centre of circular aggregate inside.

Based on the basic framework of random convex aggregate, we insert several new vertexes which located in the area between circular aggregate and convex aggregate to constitute a new polygon. The new inserted vertex requires the following conditions to be satisfied:

(a) The new vertex should not be beyond the scope of specimen.

(b) The newly formed extensional polygon should be a convex polygon.

(c) The newly formed aggregates have no overlap region with each other.

Using the method mentioned above, the two-dimensional random convex aggregate model for RAC (shown in Figure 4) is translated by the two-dimensional random circular aggregate model.

In this paper, the projection method is applied to the attribute interval recognition of arbitrary element in RAC specimen. By using computer programming, we can judge the states of recycled coarse aggregate, new cement mortar, 


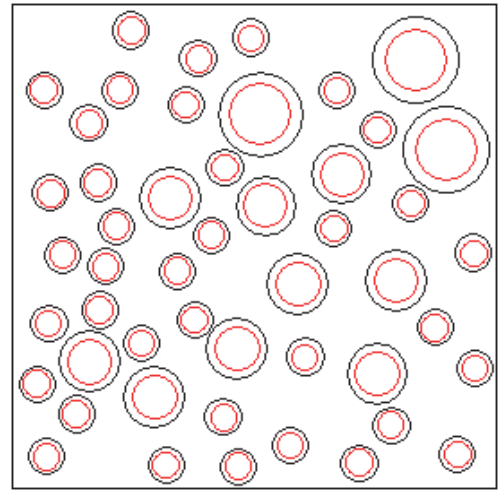

(a) A specimen of $100 \mathrm{~mm} \times 100 \mathrm{~mm}$

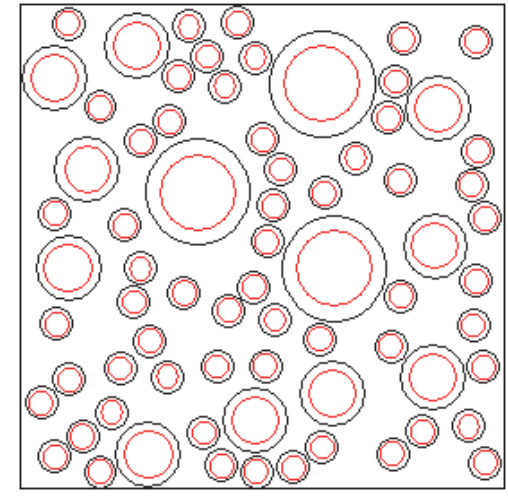

(b) A specimen of $150 \mathrm{~mm} \times 150 \mathrm{~mm}$

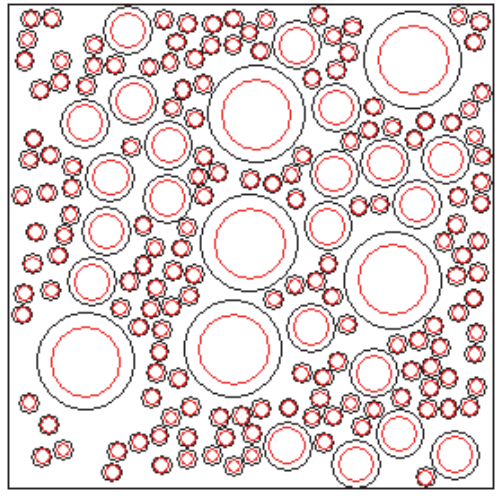

(c) A specimen of $300 \mathrm{~mm} \times 300 \mathrm{~mm}$

FIGURE 3: Random circular aggregate model of RAC.

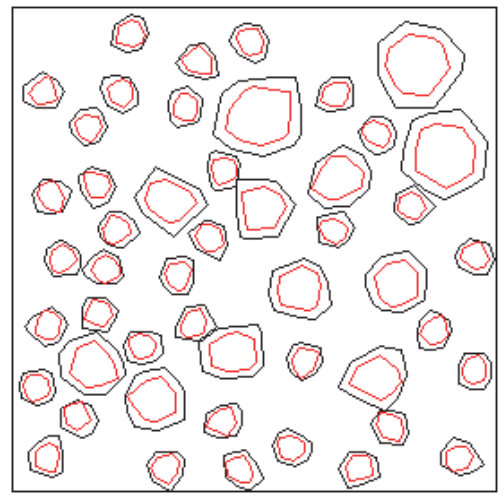

(a) A specimen of $100 \mathrm{~mm} \times 100 \mathrm{~mm}$

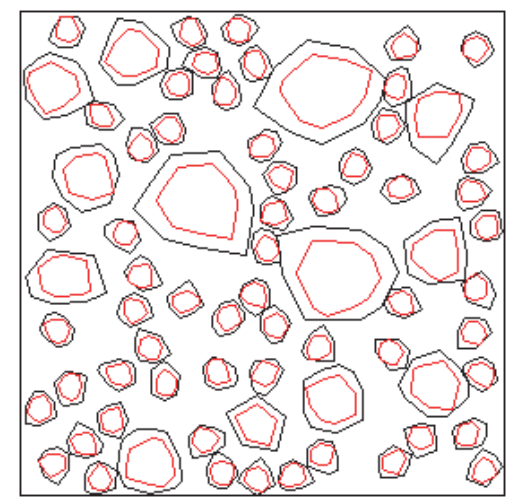

(b) A specimen of $150 \mathrm{~mm} \times 150 \mathrm{~mm}$

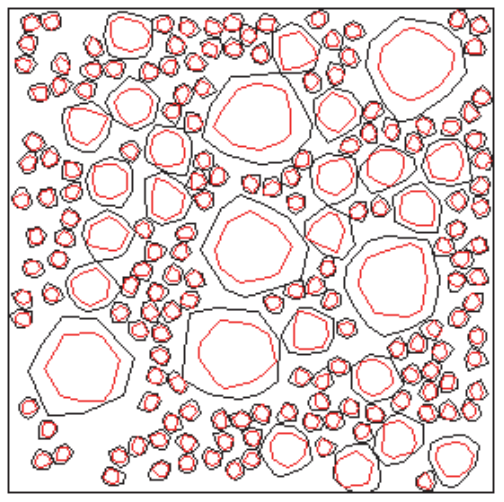

(c) A specimen of $300 \mathrm{~mm} \times 300 \mathrm{~mm}$

FIGURE 4: Random convex polygon aggregate model of recycled aggregate concrete.

old cement mortar, new interfacial transition zone (ITZ), and old ITZ. The model is shown in Figure 5.

\section{Simulation on Uniaxial Compress Test of RAC}

5.1. Loading Mode. Based on the BFEM on potential energy principle for damage mechanics problem, this paper simulated the concrete test under uniaxial compression (shown in Figure 6(a)). Therefore, the load patterns can be simplified by Figure 6(b) which was loaded on the upper surface of specimen by the displacement steps of $0.005 \mathrm{~mm} / \mathrm{step}$ and constrained by hinged bearing.

5.2. Material Parameter Values. Referring to the experimental results from $[3,11,26]$ and the damage constitutive model of materials, the material parameters of RAC specimens (presented in Table 1) are selected for the numerical simulations.

5.3. Failure Process of RAC Specimens. A specimen of $100 \mathrm{~mm}$ $\times 100 \mathrm{~mm}$, a specimen of $150 \mathrm{~mm} \times 150 \mathrm{~mm}$, and a specimen of $300 \mathrm{~mm} \times 300 \mathrm{~mm}$ are chosen as the representative models to observe the failure patterning of different size of RAC

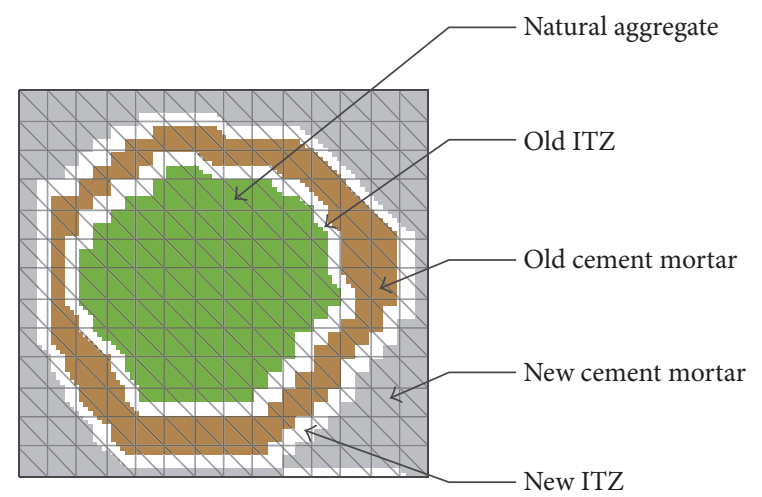

FIGURE 5: Attribute interval recognition of convex polygon recycled coarse aggregate.

specimens by uniaxial compression, and they are shown in Table 2.

5.4. Results of Uniaxial Compressive Strength. Three specimens of $100 \mathrm{~mm} \times 100 \mathrm{~mm}$ with different random aggregate distributions are simulated, and the uniaxial compressive stress-strain curves are shown in Figure 7(a). 


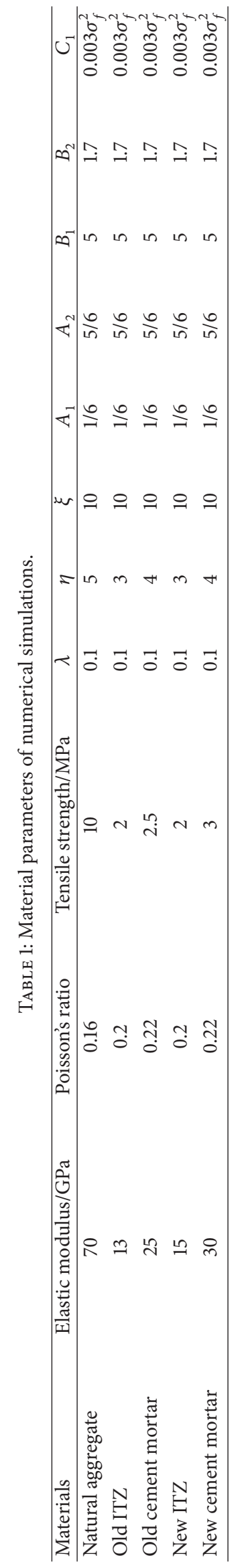


TABLE 2: The failure patterning of different size of RAC specimens under uniaxial compression.

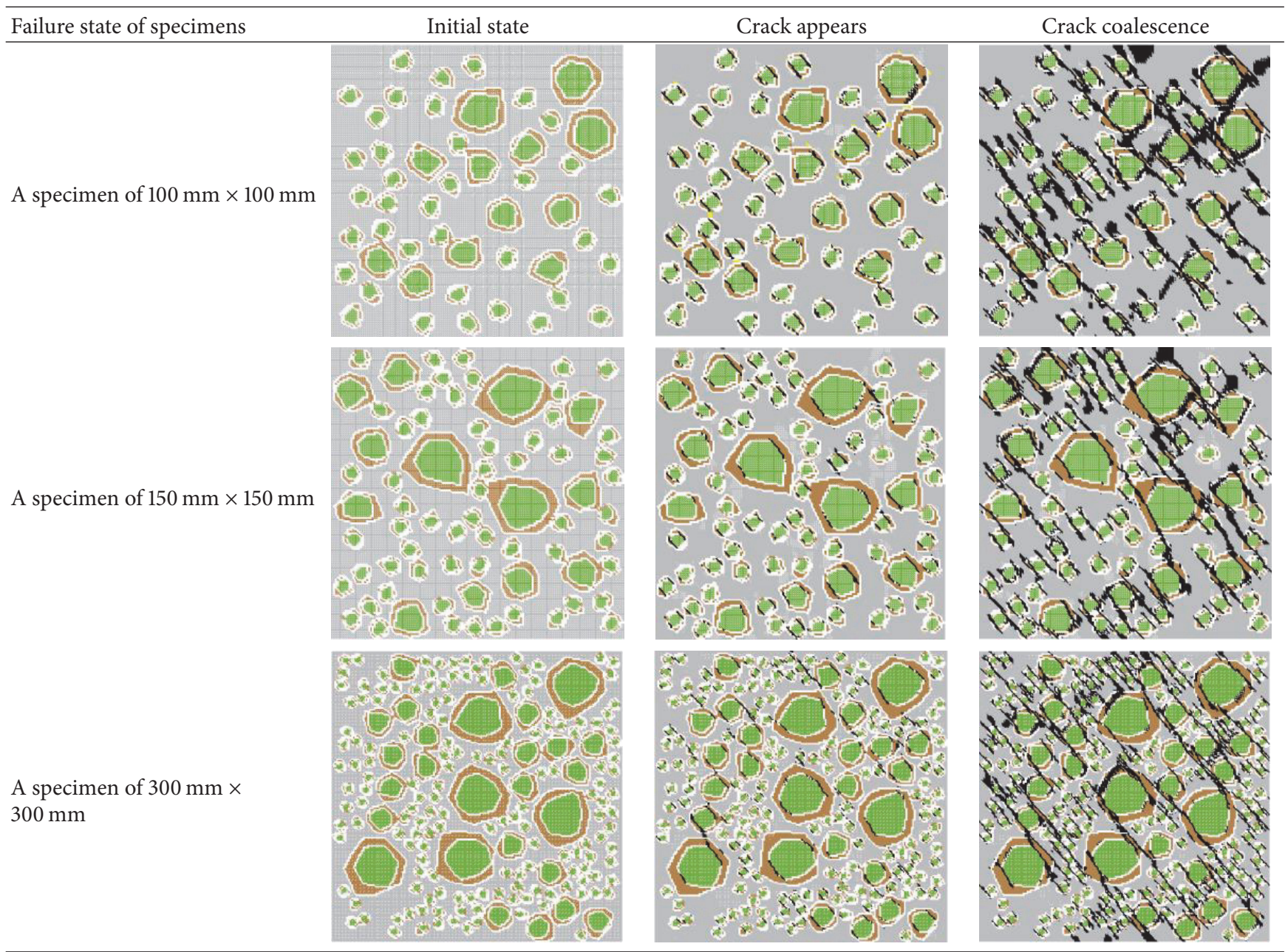

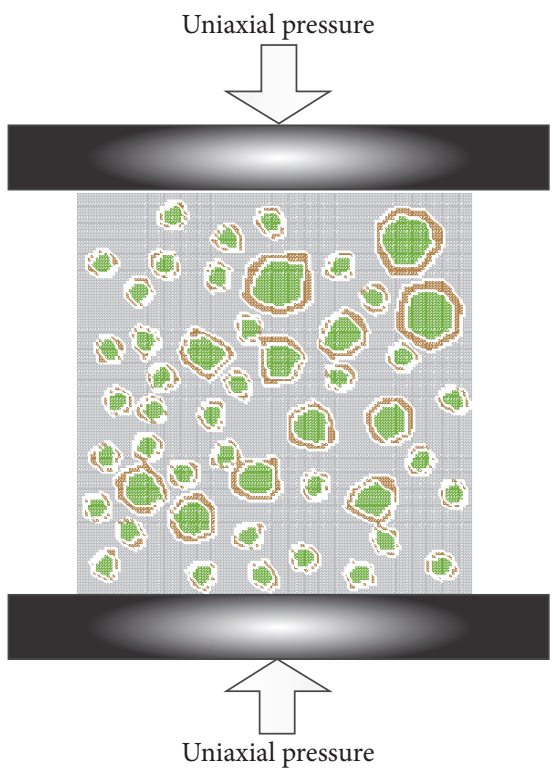

(a)

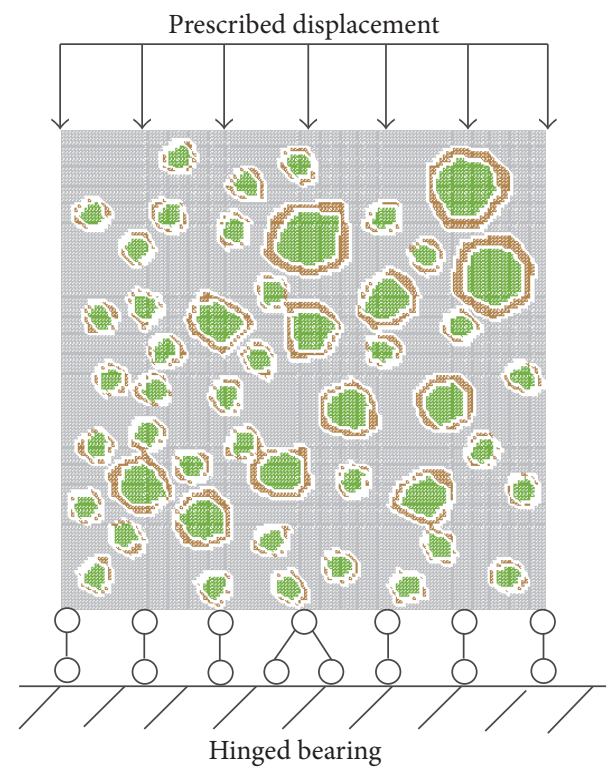

(b)

FIGURE 6: Compressive loading model. 


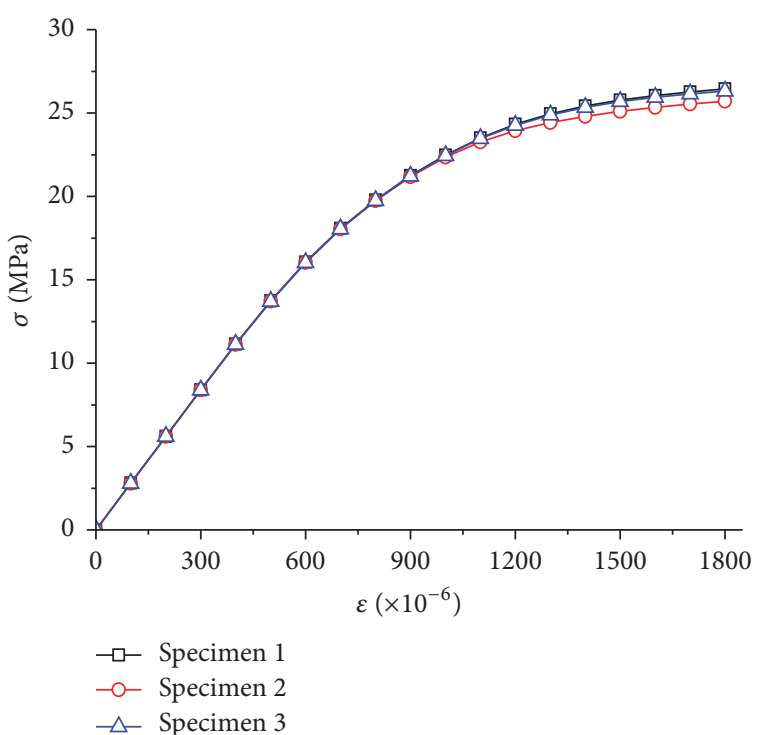

(a) Specimens of $100 \mathrm{~mm} \times 100 \mathrm{~mm}$

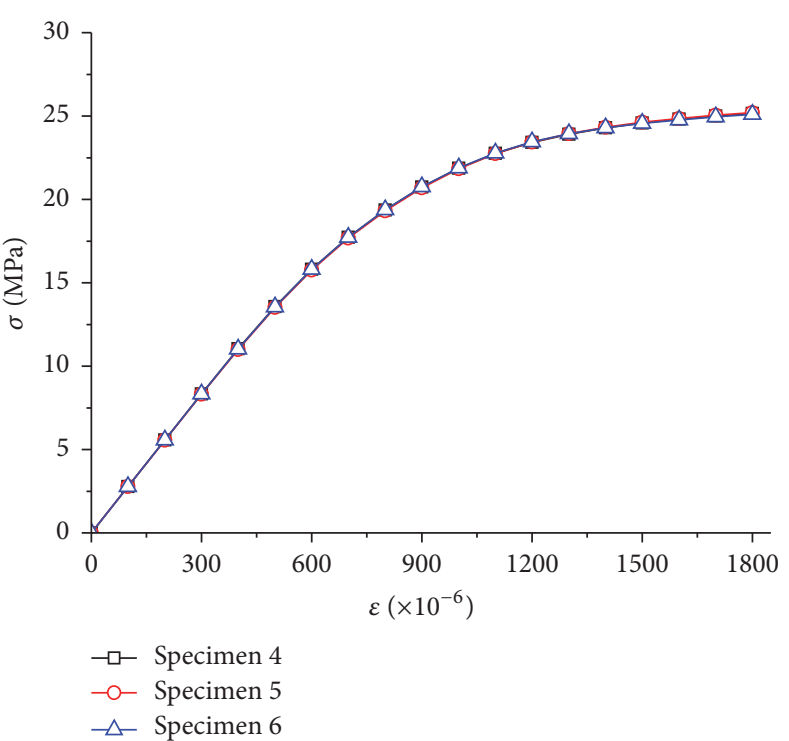

(b) Specimens of $150 \mathrm{~mm} \times 150 \mathrm{~mm}$

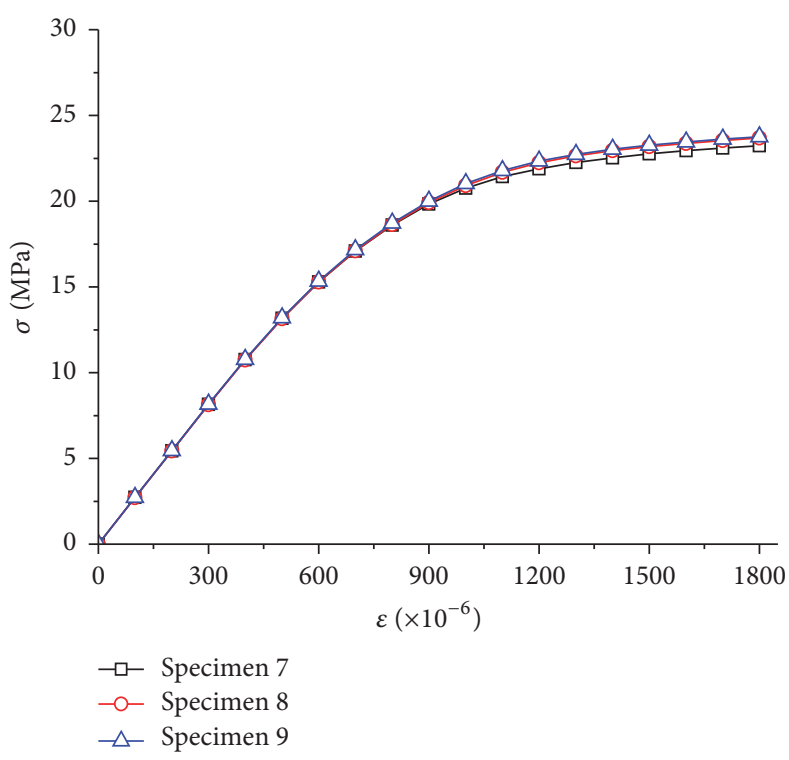

(c) Specimens of $300 \mathrm{~mm} \times 300 \mathrm{~mm}$

FIGURE 7: Uniaxial compressive stress-strain curve of RAC specimens.

Similarly, the uniaxial compressive stress-strain curves of three specimens of $150 \mathrm{~mm} \times 150 \mathrm{~mm}$ and three specimens of $300 \mathrm{~mm} \times 300 \mathrm{~mm}$ are shown in Figures 7(b) and 7(c), respectively.

The calculation results are shown as follows:

(a) The uniaxial compressive strengths of the three specimens of $100 \mathrm{~mm} \times 100 \mathrm{~mm}$ are $26.44 \mathrm{MPa}, 25.71 \mathrm{MPa}$, and $26.31 \mathrm{MPa}$, and the average strength is $26.15 \mathrm{MPa}$.

(b) The uniaxial compressive strengths of the three specimens of $150 \mathrm{~mm} \times 150 \mathrm{~mm}$ are $25.15 \mathrm{MPa}, 25.21 \mathrm{MPa}$, and $25.10 \mathrm{MPa}$, and the average strength is $25.15 \mathrm{MPa}$.

(c) The uniaxial compressive strengths of the three specimens of $300 \mathrm{~mm} \times 300 \mathrm{~mm}$ are $23.24 \mathrm{MPa}, 23.68 \mathrm{MPa}$, and $23.75 \mathrm{MPa}$, and the average strength is $23.56 \mathrm{MPa}$.
For the specimens of $100 \mathrm{~mm} \times 100 \mathrm{~mm}$, the uniaxial compressive strength of $26.15 \mathrm{MPa}$ is coincided with the result of $26.7 \mathrm{MPa}$ in the test [27].

5.5. Size Effect of Uniaxial Compressive Strength. To explore the size effect of uniaxial compressive strength with the same loading conditions, we calculate the average values of three specimens in the dimension of $100 \mathrm{~mm} \times 100 \mathrm{~mm}, 150 \mathrm{~mm}$ $\times 150 \mathrm{~mm}$, and $300 \mathrm{~mm} \times 300 \mathrm{~mm}$, respectively. The average compressive stress-strain curves are shown in Figure 8, and the uniaxial compressive strengths are shown in Table 3.

5.6. Influences of the Contents of Old Mortar on Numerical Simulation. The recycled aggregates are made from demolished concrete by a series of measures like crushing, cleaning, 


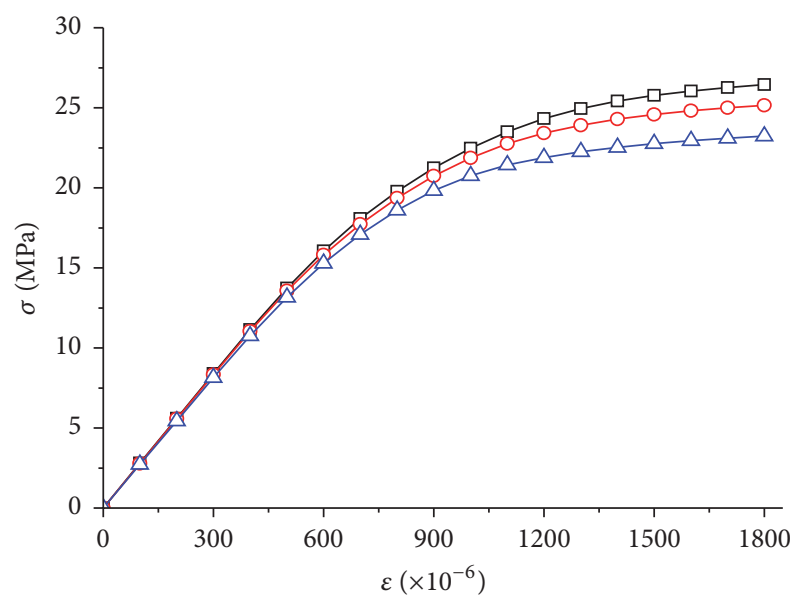

$\neg \square$ Specimens of $100 \mathrm{~mm} \times 100 \mathrm{~mm}$

- - Specimens of $150 \mathrm{~mm} \times 150 \mathrm{~mm}$

$\neg-$ Specimens of $300 \mathrm{~mm} \times 300 \mathrm{~mm}$

FIGURE 8: The average compressive stress-strain curves of RAC specimens in three dimensions.

TABLE 3: The average uniaxial compressive strength of different sizes of RAC specimens.

\begin{tabular}{lc}
\hline Dimensions of RAC & Means of compressive strength/MPa \\
\hline $100 \mathrm{~mm} \times 100 \mathrm{~mm}$ & 26.15 \\
$150 \mathrm{~mm} \times 150 \mathrm{~mm}$ & 25.15 \\
$300 \mathrm{~mm} \times 300 \mathrm{~mm}$ & 23.56 \\
\hline
\end{tabular}

TABLE 4: Compressive strengths of RAC with different mass contents of old mortar.

\begin{tabular}{lc}
\hline Mass contents of old mortar & Compressive strength/MPa \\
\hline $32 \%$ & 26.76 \\
$42 \%$ & 26.31 \\
$52 \%$ & 25.39 \\
\hline
\end{tabular}

and grading. Due to the different degrees of processing technology, the contents of old mortar adhered on natural aggregates are uncertain.

As early as 1984, Rasheeduzzafar and Khan [28] concluded that the weakest link in RAC depended on the relative strength of the old mortar and new mortar. Etxeberria et al. [29] found that the adhered old mortar on the RCA was the weakest point. Therefore, this research assumed the contents of old mortar adhered to the recycled aggregates play an important role in the uniaxial compression behavior and applied three different mass contents (32\%, $42 \%$, and 52\%) to the RAC specimens of $100 \mathrm{~mm} \times 100 \mathrm{~mm}$. The numerical RAC models, the compressive stress-strain curve, and the compressive strengths are shown in Figures 9 and 10 and Table 4 , respectively.

5.7. Influences of ITZ Characteristics on Numerical Simulation. Through the failure patterning of RAC specimens, we may discover that microcracks first appear in the ITZ between

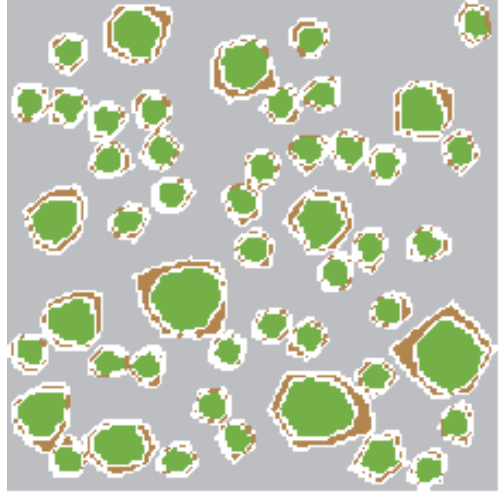

(a) Mass contents of $32 \%$

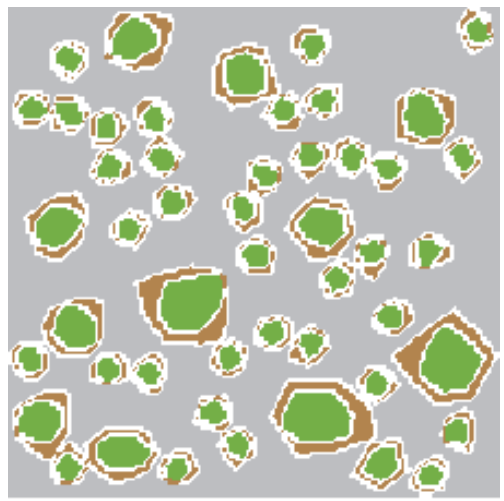

(b) Mass contents of $42 \%$

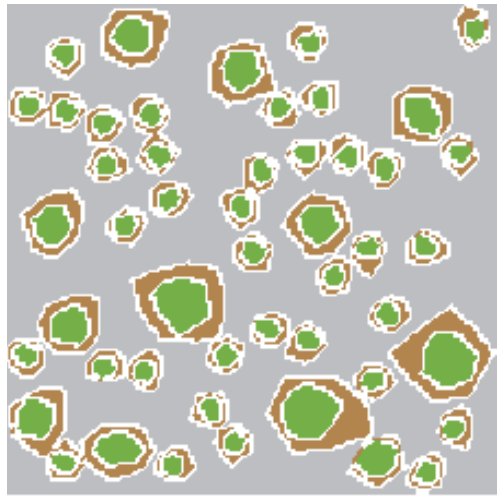

(c) Mass contents of $52 \%$

FIGURE 9: RAC models with different mass contents of old mortar.

the zones of aggregate and cement mortar. Subsequently, the cracks will propagate, intersect, and run through the specimen till it is destroyed. The strength of interface performance plays an important role in the mechanical properties of recycled concrete materials. It is difficult to study the interfacial mechanical properties of recycled concrete materials by means of experiments, and the numerical analysis method will be a powerful analytical method. At present, the studies on the interfacial mechanical properties of recycled concrete materials by using numerical analysis method are relatively few.

In order to explore the influence of the tensile strength of ITZ, several numerical values were used by some researchers; 


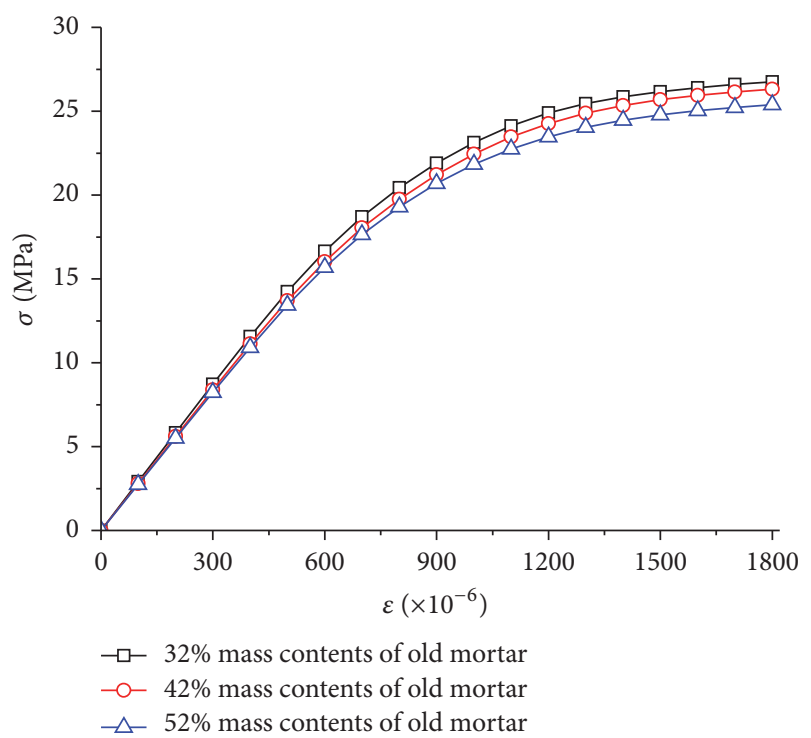

FIGURE 10: Uniaxial compressive stress-strain curve of RAC specimens with different mass contents of old mortar.

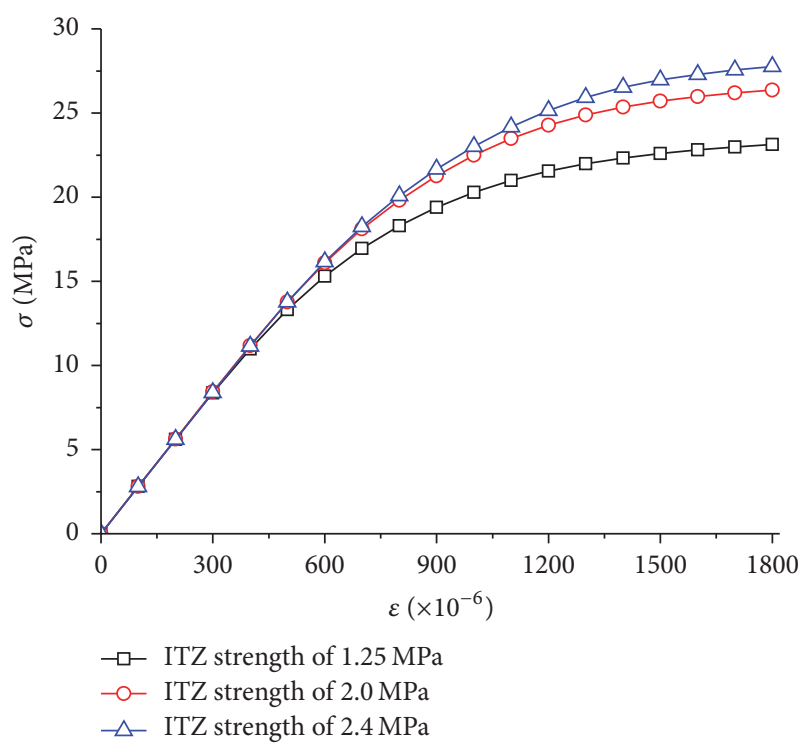

FIGURE 11: The compressive stress-strain curve of RAC specimen of $100 \mathrm{~mm} \times 100 \mathrm{~mm}$ with different tensile strengths of ITZ.

for instance, the strength values of 1.25 MPa were applied to the concrete area between matrix and aggregate in the lattice model by Chiaia et al. [26]. Horsch and Wittmann [30] chose $2.0 \mathrm{MPa}$ as the tensile strength of ITZ to investigate its influences. Xiao et al. [31] used $2.40 \mathrm{MPa}$ as the tensile strengths of ITZ in numerical concrete. Therefore, the three different tensile strengths are adopted in this paper to explore the effect on the uniaxial compressive strength with RAC specimens of $100 \mathrm{~mm} \times 100 \mathrm{~mm}$.

The compressive stress-strain curves are shown in Figure 11. The compressive strengths of RAC with different tensile strengths of ITZ are shown in Table 5.
TABLE 5: Compressive strengths of RAC with different tensile strengths of ITZ.

\begin{tabular}{lc}
\hline Tensile strength of ITZ/MPa & Compressive strength/MPa \\
\hline 1.25 & 23.13 \\
2.0 & 26.36 \\
2.4 & 27.75 \\
\hline
\end{tabular}

\section{Conclusions}

(1) This paper analyzed the uniaxial compressive strengths, size effects on strength, and damage processes of RAC using the Base Force Element Method (BFEM) on mesolevel. The numerical results show that the uniaxial compressive strength of RAC specimens decreases with increasing specimen size, and it is agreeing with the test results. The research works show that the random convex aggregate model and the BFEM with the curve damage model can be used for simulating the relationship between microstructure and mechanical properties of RAC.

(2) Taking the real graduation and content of recycled aggregates into consideration, this paper proposed a new model of numerical RAC, random convex aggregate, model which contains natural coarse aggregate, new mortar, new interfacial transition zone (ITZ), old mortar, and old ITZ. The model can reflect the characteristics of RAC specimens more authentically than the random circular aggregate model, and it is proved to be feasible by the numerical test result. The relationships of mesostructure and macroscopic mechanical performance of RAC can be analyzed in a simple and feasible way with this model.

(3) The failure pattern of numerical RAC under uniaxial compression shows that the destruction process of specimen can be described as the initiation, propagation, and cutthrough of cracks at mesoscale level, which is in accordance with the real phenomena.

(4) The failure pattern also shows that the microcracks first appear in the area of interfacial transition zone (ITZ) with the increase of compressive loading; therefore, a hypothesis that ITZ is the weak part of RAC is raised by this study. Moreover, it can be seen clearly that the compressive strength of RAC specimen increases obviously as the tensile strength of ITZ increases in above qualitative analysis. However, more systemic experiments are necessary to be done to explore the contributions which ITZ made quantitatively in years to come.

(5) Three different mass contents are used in the RAC models to explore their influences on the uniaxial compressive strengths. The results indicated that the compressive strength of RAC specimen increases as the tensile strength of ITZ increases, and this may be due to the fact that the aggregates with low old mortar contents are much closer to the natural aggregates which make the mechanical property of RAC specimens much closer to the concrete.

\section{Competing Interests}

The authors declare that there is no conflict of interests. 


\section{Acknowledgments}

This work is supported by National Science Foundation of China (10972015, 11172015), Beijing Natural Science Foundation (8162008), and Preexploration Project of Key Laboratory of Urban Security and Disaster Engineering, Ministry of Education, Beijing University of Technology (USDE201404).

\section{References}

[1] F. H. Wittmann, P. E. Roelfstra, and H. Sadouki, "Simulation and analysis of composite structures," Materials Science and Engineering, vol. 68, no. 2, pp. 239-248, 1985.

[2] Z. P. Bažant, M. R. Tabbara, M. T. Kazemi, and G. PyaudierCabot, "Random particle model for fracture of aggregate or fiber composites," Journal of Engineering Mechanics, vol. 116, no. 8, pp. 1686-1705, 1990.

[3] G. Liu and Z. Wang, "Numerical simulation study of fracture of concrete materials using random aggregate model," Journal of Tsinghua University, vol. 36, no. 1, pp. 84-89, 1996 (Chinese).

[4] W. C. Zhu and C. A. Tang, "Numerical simulation on shear fracture process of concrete using mesoscopic mechanical model," Construction and Building Materials, vol. 16, no. 8, pp. 453-463, 2002.

[5] H. Chen, H. Ma, J. Tu, G. Cheng, and J. Tang, "Parallel computation of seismic analysis of high arch dam," Earthquake Engineering and Engineering Vibration, vol. 7, no. 1, pp. 1-11, 2008.

[6] X. Du, L. Jin, and G. Ma, "Meso-element equivalent method for the simulation of macro mechanical properties of concrete," International Journal of Damage Mechanics, vol. 22, no. 5, pp. 617-642, 2013.

[7] L. Jin, X. L. Du, and G. W. Ma, "Macroscopic effective moduli and tensile strength of saturated concrete," Cement and Concrete Research, vol. 42, no. 12, pp. 1590-1600, 2012.

[8] X. Du, L. Jin, and G. Ma, "Macroscopic effective mechanical properties of porous dry concrete," Cement and Concrete Research, vol. 44, pp. 87-96, 2013.

[9] X. Du and L. Jin, "Meso-scale numerical investigation on cracking of cover concrete induced by corrosion of reinforcing steel," Engineering Failure Analysis, vol. 39, pp. 21-33, 2014.

[10] X. L. Du, L. Jin, and G. W. Ma, "A meso-scale analysis method for the simulation of nonlinear damage and failure behavior of reinforced concrete members," International Journal of Damage Mechanics, vol. 22, no. 6, pp. 878-904, 2013.

[11] J. Xiao, W. Li, D. J. Corr, and S. P. Shah, "Simulation study on the stress distribution in modeled recycled aggregate concrete under uniaxial compression," Journal of Materials in Civil Engineering, vol. 25, no. 4, pp. 504-518, 2013.

[12] Z. M. Wang, A. K. H. Kwan, and H. C. Chan, "Mesoscopic study of concrete I: generation of random aggregate structure and finite element mesh," Computers \& Structures, vol. 70, no. 5, pp. 533-544, 1999.

[13] C.-B. Du and L.-G. Sun, "Numerical simulation of aggregate shapes of two-dimensional concrete and its application," Journal of Aerospace Engineering, vol. 20, no. 3, pp. 172-178, 2007.

[14] Y. J. Peng and Y. H. Liu, "Base force element method of complementary energy principle for large rotation problems," Acta Mechanica Sinica, vol. 25, no. 4, pp. 507-515, 2009.

[15] Y. J. Peng, Z. L. Dong, B. Peng, and Y. Liu, "Base force element method (BFEM) on potential energy principle for elasticity problems," International Journal of Mechanics and Materials in Design, vol. 7, no. 3, pp. 245-251, 2011.

[16] Y. J. Peng, Z. L. Dong, B. Peng, and N. N. Zong, “The application of $2 \mathrm{D}$ base force element method (BFEM) to geometrically nonlinear analysis," International Journal of Non-Linear Mechanics, vol. 47, no. 3, pp. 153-161, 2012.

[17] Y.-J. Peng, J.-W. Pu, B. Peng, and L.-J. Zhang, "Two-dimensional model of base force element method (BFEM) on complementary energy principle for geometrically nonlinear problems," Finite Elements in Analysis and Design, vol. 75, pp. 78-84, 2013.

[18] Y. J. Peng, L. J. Zhang, J. W. Pu, and Q. Guo, "A two-dimensional base force element method using concave polygonal mesh," Engineering Analysis with Boundary Elements, vol. 42, pp. 4550, 2014.

[19] Y. Peng, N. Zong, L. Zhang, and J. Pu, "Application of 2D base force element method with complementary energy principle for arbitrary meshes," Engineering Computations, vol. 31, no. 4, pp. 691-708, 2014.

[20] Y. Liu and Y. Peng, "Base force element method (BFEM) on complementary energy principle for linear elasticity problem," Science China: Physics, Mechanics \& Astronomy, vol. 54, no. 11, pp. 2025-2032, 2011.

[21] Y. Peng, Y. Liu, J. Pu, and L. Zhang, "Application of base force element method to mesomechanics analysis for recycled aggregate concrete," Mathematical Problems in Engineering, vol. 2013, Article ID 292801, 8 pages, 2013.

[22] Y. C. Gao, "A new description of the stress state at a point with applications," Archive of Applied Mechanics, vol. 73, no. 3-4, pp. 171-183, 2003.

[23] J. Lemaitre and J. Chaboche, Mechanics of Solid Materials, Cambridge University Press, Cambridge, Uk, 1990.

[24] J. Qian and J. Zhou, "Two concrete damage models and their application," Journal of Hohai University, vol. 17, no. 3, pp. 4043, 1989 (Chinese).

[25] J. C. Walraven and H. W. Reinhardt, "Theory and experiments on the mechanical behaviour of cracks in plain and reinforced concrete subjected to shear loading," HERON, vol. 26, no. 1, 1981.

[26] B. Chiaia, A. Vervuurt, and J. G. M. Van Mier, "Lattice model evaluation of progressive failure in disordered particle composites," Engineering Fracture Mechanics, vol. 57, no. 2-3, pp. 301-318, 1997.

[27] J. Xiao, "Experimental investigation on complete stress-strain curve of recycled concrete under uniaxial loading," Journal of Tongji University (Natural Science), vol. 35, no. 11, pp. 1445-1449, 2007 (Chinese).

[28] Rasheeduzzafar and A. Khan, "Recycled concrete-a source for new aggregate," Cement, Concrete and Aggregates, vol. 6, no. 1, pp. 17-27, 1984.

[29] M. Etxeberria, E. Vázquez, and A. Marí, "Microstructure analysis of hardened recycled aggregate concrete," Magazine of Concrete Research, vol. 58, no. 10, pp. 683-690, 2006.

[30] T. Horsch and F. H. Wittmann, "Three-dimensional numerical concrete applied to investigate effective properties of composite materials," in Fracture Mechanism of Concrete Structures, pp. 5764, 2001.

[31] J. Xiao, W. Li, D. J. Corr, and S. P. Shah, "Effects of interfacial transition zones on the stress-strain behavior of modeled recycled aggregate concrete," Cement and Concrete Research, vol. 52, pp. 82-99, 2013. 

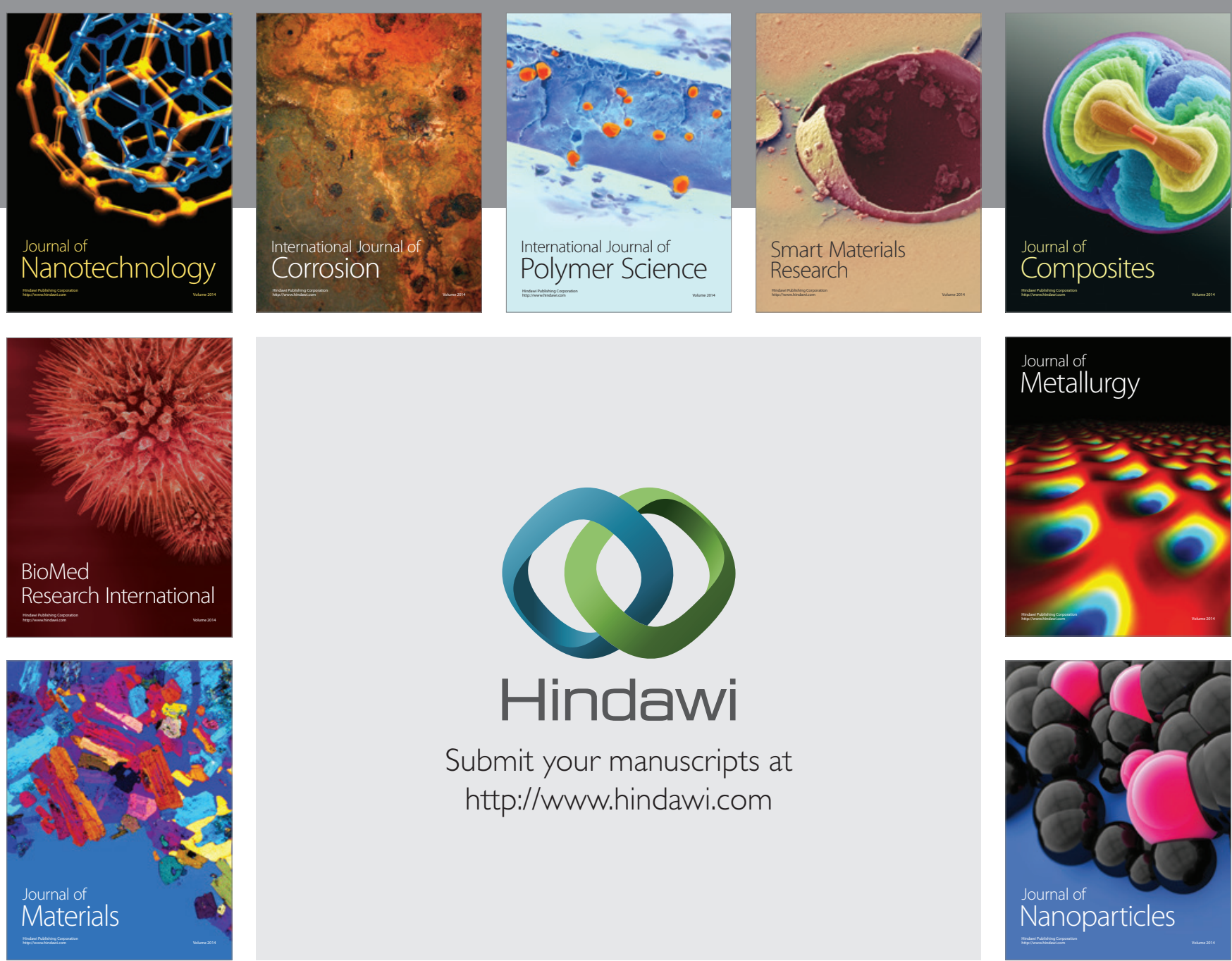

\section{Hindawi}

Submit your manuscripts at

http://www.hindawi.com

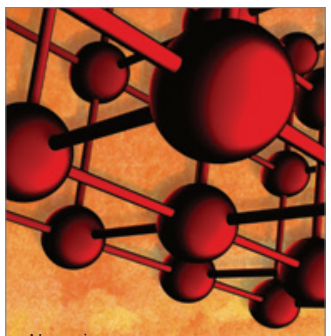

Materials Science and Engineering
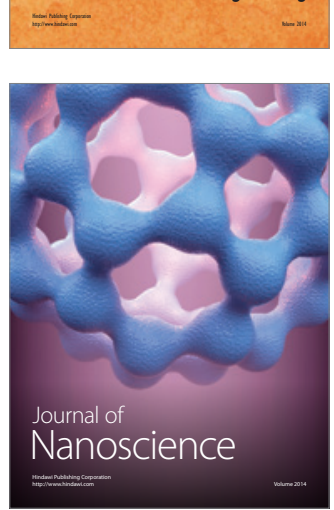
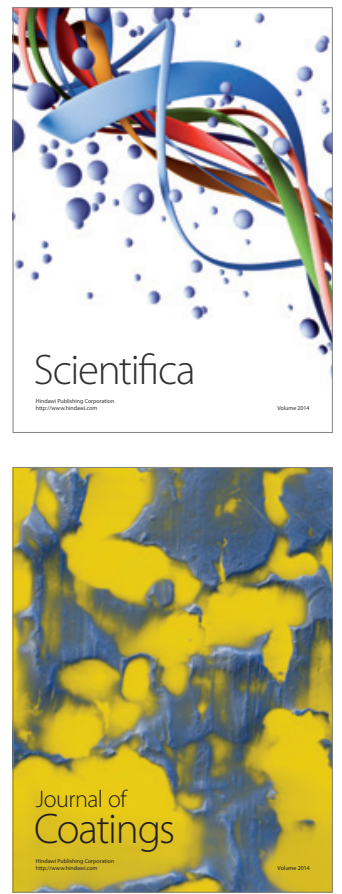
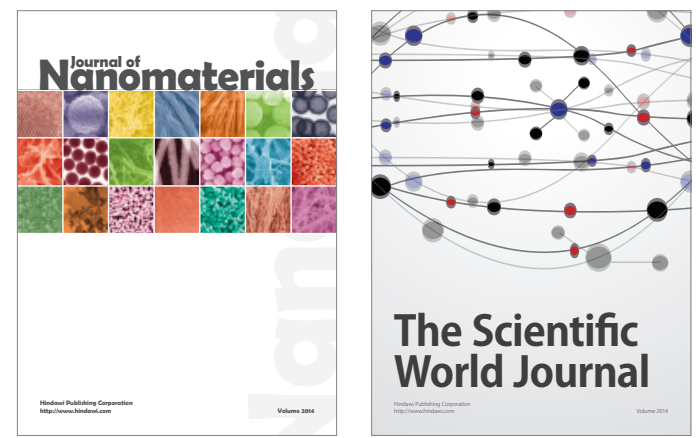

The Scientific World Journal
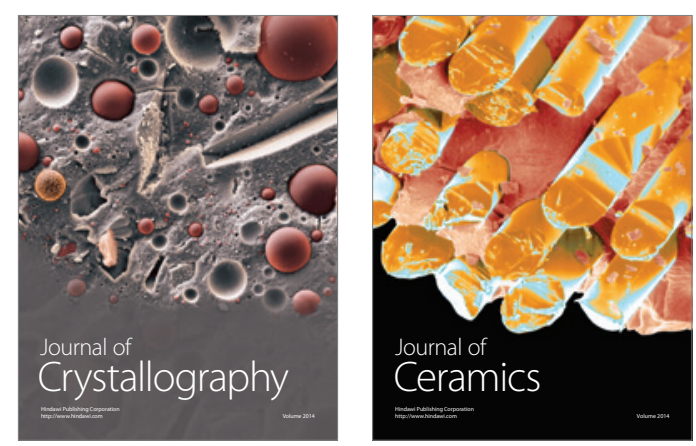
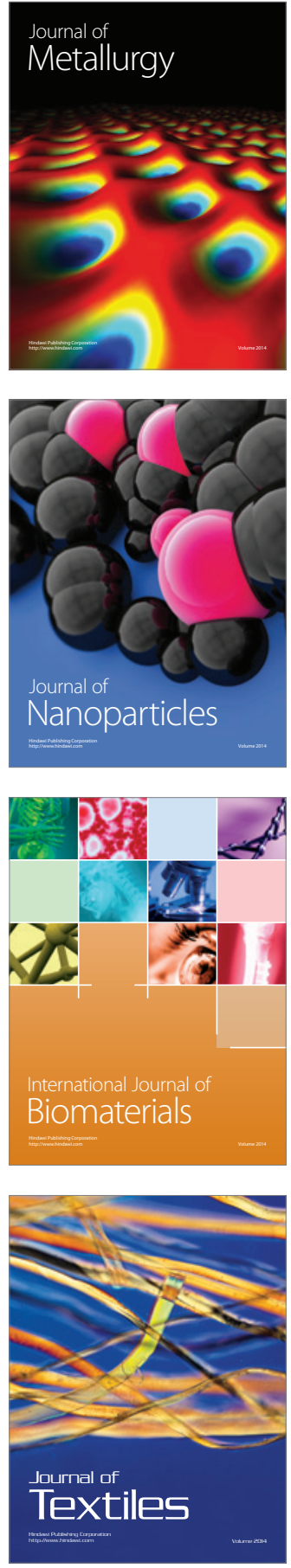